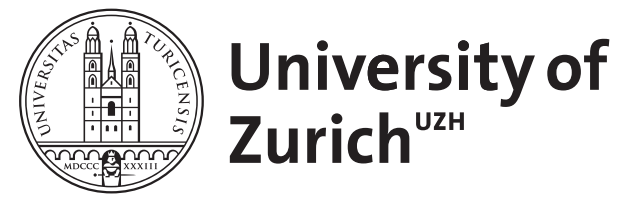

\title{
Regulation of hepatic and intestinal bile acid transport by FXR-controlled pathways
}

\author{
Eloranta, J J ; Kullak-Ublick, G A
}

Posted at the Zurich Open Repository and Archive, University of Zurich

ZORA URL: https://doi.org/10.5167/uzh-56071

Book Section

Accepted Version

Originally published at:

Eloranta, J J; Kullak-Ublick, G A (2007). Regulation of hepatic and intestinal bile acid transport by FXR-controlled pathways. In: Keppler, D; Beuers, U; Leuschner, U; Stiehl, A; Trauner, M; Paumgartner, G. Bile Acids: Biological Actions and Clinical Relevance. Dordrecht (NL): Springer, 115-120. 


\section{Regulation of hepatic and intestinal bile acid transport by FXR-controlled pathways}

JYRKI J. ELORANTA and GERD A. KULLAK-UBLICK

Correspondence:

Gerd A. Kullak-Ublick, M.D.

Division of Clinical Pharmacology and Toxicology

University Hospital Zurich

Rämistrasse 100

$\mathrm{CH}-8091$ Zurich, Switzerland

(E-mail: gerd.kullak@usz.ch)

(Telephone: + 4112553652 )

(Fax: + 4112554411$)$ 


\section{OVERVIEW OF ENTEROHEPATIC BILE ACID TRANSPORTERS}

Bile acids are physiological detergents that promote absorption and excretion of cholesterol, lipids, and other hydrophobic compounds in the liver and intestine (1). Bile acids are synthesized de novo in the liver through cholesterol catabolism and stored in the gall bladder, from which they are postprandially released into the intestine. From the ileum bile acids are returned back to the liver via portal blood. The enterohepatic circulation of bile acids is a highly efficient process in healthy individuals, and is of crucial importance for the maintenance of bile flow and hepatic secretory function. The recycling of bile acids between the liver and intestine is mediated by specific transporter proteins, expressed at the plasma membranes of hepatocytes and enterocytes in a polarized manner (2).

The chief transporter responsible for the excretion of bile acids from hepatocytes into bile canaliculi is the bile salt export pump (BSEP, $A B C B 11$ ) (3), which belongs to the ATPbinding cassette $(\mathrm{ABC})$ transporter family (4). Whereas BSEP exports monovalent bile acids, another $\mathrm{ABC}$ transporter at the canalicular membrane of hepatocytes, multidrug resistance-asscoiated protein 2 (MRP2, $A B C C 2)$, excretes divalent and sulphated/glucuronidated bile acids into bile (5). While bile acids are the most prominent (60-70\%) components of bile, it also contains phospholipids and cholesterol, which form mixed micelles with the bile acids. The latter two components are translocated into bile by further canalicular $\mathrm{ABC}$ family transporters, namely the multidrug resistance protein 3 (MDR3, $A B C B 4$ ) and the heterodimeric ABCG5/ABCG8, respectively (4).

After their passage to the intestinal lumen, bile acids are taken up into ileocytes via the apical sodium-dependent transporter (ASBT, SLC10A2) (6), the activity of which is coupled with cotransport of sodium. At the basolateral membranes of ileal enterocytes, bile acids are extruded into portal blood by the organic solute transporter heterodimer OST $\alpha / \operatorname{OST} \beta$ (7). 
The larger subunit OST $\alpha$ contains seven predicted transmembrane domains, whereas OST $\beta$ has a single membrane-spanning domain. Coexpression of OST $\alpha$ and OST $\beta$ polypeptides is required for correct localization of the heterodimer at the cell membrane and for transport activity. In agreement with its role as the intestinal bile acid efflux transporter, relative distribution of the OST $\alpha / \operatorname{OST} \beta$ heterodimer along the intestinal tract is similar to that of the bile acid uptake system ASBT.

To complete their enterohepatic circulation, bile acids are finally taken up from sinusoidal blood back into parenchymal hepatocytes by transport proteins located at the basolateral membrane. The chief hepatic uptake system for bile acids is the sodium taurocholate cotransporting polypeptide (NTCP, SLC10A1) (6), which belongs to the same SLC10 transporter family as ASBT. A member of the organic anion transporter family located at the basolateral membrane, OATP1B1 (SLCO1B1), may to a smaller degree also contribute to hepatic bile acid extraction from portal blood in a sodium-independent manner (8).

\section{INDUCTION OF HUMAN BILE ACID EFFLUX TRANSPORTERS BY THE BILE ACID RECEPTOR FXR}

Due to their detergent properties, bile acids can be intrinsically toxic to cells, hence their intracellular concentration must be tightly controlled. In addition to their role as physiological detergents, bile acids can act as signalling molecules and homeostatic regulators of their own transport and metabolism within the enterohepatic circulation. By controlling their own cellular uptake or efflux via regulation of the expression levels of bile acid transporter genes, bile acids can adjust their own intracellular concentrations. 
The chief sensor of intracellular bile acid levels and the main executor of bile acidinduced transcriptional programmes is a transcription factor of the nuclear receptor family, namely the farnesoid X receptor (FXR) (9). Bile acids directly interact with, and function as agonists ligands of, the ligand-binding domain of FXR. In accordance with its function as the bile acid receptor, FXR is most abundantly expressed in the tissues commonly exposed to bile acids: liver, intestine, and kidneys. The preferred DNA-binding sequence for FXR within its target promoters is the so-called "inverted repeat-1" motif (IR-1, inverted hexameric repeat separated by one base pair) (10), to which FXR binds as a heterodimer with another nuclear receptor, namely the retinoid $\mathrm{X}$ receptor (RXR).

In response to bile acids FXR stimulates BSEP expression via direct interaction of FXR-RXR heterodimers with an IR-1 element located in the proximal promoter of the $A B C B 11$ gene (11-13). Thus, excessive levels of bile acids lead to stimulation of their own hepatocanalicular clearance. The FXR-RXR response element is conserved between the human and rodent $A B C B 11 / A b c b 11$ promoters, in support of its functional importance. Similarly to the $A B C B 11$ gene, expression of the $A B C C 2$ gene encoding MRP2, the transporter for divalent bile acids at the canalicular membrane, can also be activated by bile acids and FXR (14). In the case of the $A B C C 2$ promoter, FXR transactivates through an atypical "everted repeat-8" (ER-8) motif. In addition to the canalicular bile acid transporter genes, bile acid-activated FXR can induce the expression of the $A B C B 4$ gene encoding MDR3, the phospholipid transporter at the canalicular membrane of hepatocytes (15). Thus, bile acids, by activating FXR, induce the excretion of both bile acids (BSEP, MRP2) and phospholipids (MDR3) into bile in a coordinated manner.

In an analogous manner to the $A B C B 11$ gene, expression of the two genes encoding the heterodimeric bile acid efflux system in the intestine, OST $\alpha / \mathrm{OST} \beta$ are induced by bile acids through direct binding of FXR-RXR heterodimers to the two human OST promoters 
$(16,17)$. While the regulatory regions of the $O S T \beta$ promoter appear to harbour a single IR-1like motif that mediates binding by FXR-RXR, the human OST $\alpha$ promoter contains two adjacent IR-1-like FXR response elements, both of which are functional and required for maximal induction by bile acids. In addition to established cell lines, both OST $\alpha$ and OST $\beta$ gene expression can be induced by bile acids in short-term tissue culture of human ileal biopsies. Further physiological evidence in support of the induction of OST gene expression by bile acids is provided by a study showing that both mRNA and protein levels of OST $\alpha$ and OST $\beta$ are increased in cholestatic liver tissue of patients suffering from primary biliary cirrhosis (18).

\section{SUPPRESSION OF HUMAN BILE ACID UPTAKE TRANSPORTERS BY THE BILE ACID RECEPTOR FXR}

In keeping with the model that the bile acid sensor FXR elicits hepatoprotective mechanisms aiming at decreasing the intracellular bile acid load, activation of FXR by elevated intracellular levels of bile acids also results in downregulation of genes encoding enterohepatic bile acid uptake sytems. In rodent models of cholestasis, expression of the hepatic bile acid uptake system Ntcp is suppressed at both the protein and mRNA level (19). Importantly, certain human cholestatic states, such as advanced stage primary biliary cirrhosis and cholestatic alcoholic hepatitis, are also associated with reduced NTCP expression (20,21). We have recently shown that the mechanism of down-regulation of the human SLC10A1 gene, encoding NTCP, in response to bile acids involves a bile acidinducible repressor of the nuclear receptor family, known as the small heterodimer partner (SHP) (22). SHP is an unusual member of the nuclear receptor family, since it lacks any 
direct DNA-binding activity (23). The promoter of the SHP gene is itself a target for transcriptional activation by ligand-bound FXR $(24,25)$. Thus, in response to elevated bile acids, FXR-induced SHP negatively targets a DNA-binding transactivator of the SLC10A1 gene, the glucocorticoid receptor (GR). The negative interference of GR by SHP involves direct interaction between the two proteins, which may block the recruitment of the transcriptional coactivator PGC-1 $\alpha$ to the human SLC10A1 promoter $(22,26)$.

The bile acid-FXR-SHP cascade also suppresses transcription of the SLCO1B1 gene encoding the OATP1B1 transporter, which may contribute to bile acid uptake at the basolateral membranes of hepatocytes (27). The molecular target of SLCO1B1 downregulation by bile acids is the liver-enriched transcription factor HNF-1 $1 \alpha$, which is a strong DNA-binding transactivator of the $S L C O 1 B 1$ promoter. The regulatory region of the $H N F$ $1 \alpha$ gene itself contains a DNA-binding motif for the nuclear receptor HNF-4 $\alpha$, the transcriptional activity of which is targeted for negative interference by the SHP protein.

HNF-4 $\alpha$ also functions as a common transactivator of hepatic drug transporter genes, such as the human SLC22Al and SLC22A7 genes, which encode polyspecific drug transporters OCT1 and OAT2, respectively, both located at the basolateral membranes of hepatocytes $(28,29)$. The bile acid-induced transcriptional repressor SHP interferes with transactivation by HNF- $4 \alpha$ in the context of both the SLC22A1 and SLC22A7 genes. Thus, in conditions of elevated intracellular bile acid concentrations, the expression of two major human drug uptake systems at the basolateral hepatic membranes may be reduced. This could restrict the amount of drugs xenobiotics that enter hepatocytes, when intracellular levels of toxic bile acids are already elevated.

In an analogous manner to NTCP, bile acids also suppress the expression of the intestinal bile acid uptake system ASBT, another member of the SLC10 transporter family in humans (30). In agreement with this, SLC10A2 gene expression has been reported to be 
reduced in patients with obstructive cholestasis (31). Similarly to the SLC1OA1 gene, the transactivator protein GR is targeted for negative interference by the bile acid-induced transcriptional repressor SHP on the SLC10A2 promoter (22,32). Interestingly, while both the SLC1OA1 and SLC1OA2 genes are transactivated by GR, the relative locations and sequence configurations of the GR response elements within the two SLC10 promoters are not conserved

\section{CONCLUDING REMARKS}

The function of enterohepatic bile acid transporters is vital for the maintenance of bile acid homeostasis in healthy individuals. Furthermore, the importance of these transporter proteins for hepatic and intestinal function is emphasized by recent demonstrations that either hereditary or acquired disturbances in the activity and/or expression of bile acid transporters are associated with cholestatic diseases. Bile acids are capable of regulating the expression of transporters that mediate the enterohepatic circulation of both bile acids and drugs via complex feedforward and feedback mechanisms. The main orchestrator of these transcriptional circuits is the nuclear receptor for bile acids, FXR, which controls the expression levels of genes encoding the major bile acid transporters at all membrane domains of enterohepatic circulation. 


\section{References}

1. Hofmann AF. The continuing importance of bile acids in liver and intestinal disease. Arch Intern Med 1999;159(22):2647-58.

2. Kullak-Ublick GA, Stieger B, Meier PJ. Enterohepatic bile salt transporters in normal physiology and liver disease. Gastroenterology 2004;126(1):322-42.

3. Arrese M, Ananthanarayanan M. The bile salt export pump: molecular properties, function and regulation. Pflugers Arch 2004;449(2):123-31.

4. Borst P, Elferink RO. Mammalian ABC transporters in health and disease. Annu Rev Biochem 2002;71:537-92.

5. Kullak-Ublick GA, Stieger B, Hagenbuch B, Meier PJ. Hepatic transport of bile salts. Semin Liver Dis 2000;20(3):273-92.

6. Hagenbuch B, Dawson P. The sodium bile salt cotransport family SLC10. Pflugers Arch 2004;447(5):566-70.

7. Dawson PA, Hubbert M, Haywood J, Craddock AL, Zerangue N, Christian WV, et al. The heteromeric organic solute transporter alpha-beta, Ostalpha-Ostbeta, is an ileal basolateral bile acid transporter. J Biol Chem 2005;280(8):6960-8.

8. Hagenbuch B, Meier PJ. Organic anion transporting polypeptides of the OATP/ SLC21 family: phylogenetic classification as OATP/ SLCO superfamily, new nomenclature and molecular/functional properties. Pflugers Arch 2004;447(5):653-65.

9. Kalaany NY, Mangelsdorf DJ. LXRS and FXR: the yin and yang of cholesterol and fat metabolism. Annu Rev Physiol 2006;68:159-91.

10. Laffitte BA, Kast HR, Nguyen CM, Zavacki AM, Moore DD, Edwards PA. Identification of the DNA binding specificity and potential target genes for the farnesoid X-activated receptor. J Biol Chem 2000;275(14):10638-47. 
11. Ananthanarayanan M, Balasubramanian N, Makishima M, Mangelsdorf DJ, Suchy FJ. Human bile salt export pump promoter is transactivated by the farnesoid X receptor/bile acid receptor. J Biol Chem 2001;276(31):28857-65.

12. Schuetz EG, Strom S, Yasuda K, Lecureur V, Assem M, Brimer C, et al. Disrupted bile acid homeostasis reveals an unexpected interaction among nuclear hormone receptors, transporters, and cytochrome P450. J Biol Chem 2001;276(42):39411-8.

13. Plass JR, Mol O, Heegsma J, Geuken M, Faber KN, Jansen PL, et al. Farnesoid X receptor and bile salts are involved in transcriptional regulation of the gene encoding the human bile salt export pump. Hepatology 2002;35(3):589-96.

14. Kast HR, Goodwin B, Tarr PT, Jones SA, Anisfeld AM, Stoltz CM, et al. Regulation of multidrug resistance-associated protein $2(\mathrm{ABCC} 2)$ by the nuclear receptors pregnane $\mathrm{X}$ receptor, farnesoid $\mathrm{X}$-activated receptor, and constitutive androstane receptor. J Biol Chem 2002;277(4):2908-15.

15. Huang L, Zhao A, Lew JL, Zhang T, Hrywna Y, Thompson JR, et al. Farnesoid X receptor activates transcription of the phospholipid pump MDR3. J Biol Chem 2003;278(51):51085-90.

16. Landrier JF, Eloranta JJ, Vavricka SR, Kullak-Ublick GA. The nuclear receptor for bile acids, FXR, transactivates human organic solute transporter-alpha and -beta genes. Am J Physiol Gastrointest Liver Physiol 2006;290(3):G476-85.

17. Lee H, Zhang Y, Lee FY, Nelson SF, Gonzalez FJ, Edwards PA. FXR regulates organic solute transporters alpha and beta in the adrenal gland, kidney, and intestine. J Lipid Res 2006;47(1):201-14.

18. Boyer JL, Trauner M, Mennone A, Soroka CJ, Cai SY, Moustafa T, et al. Upregulation of a basolateral FXR-dependent bile acid efflux transporter OSTalpha-OSTbeta in 
cholestasis in humans and rodents. Am J Physiol Gastrointest Liver Physiol 2006;290(6):G1124-30.

19. Fickert P, Zollner G, Fuchsbichler A, Stumptner C, Pojer C, Zenz R, et al. Effects of ursodeoxycholic and cholic acid feeding on hepatocellular transporter expression in mouse liver. Gastroenterology 2001;121(1):170-83.

20. Zollner G, Fickert P, Zenz R, Fuchsbichler A, Stumptner C, Kenner L, et al. Hepatobiliary transporter expression in percutaneous liver biopsies of patients with cholestatic liver diseases. Hepatology 2001;33(3):633-46.

21. Zollner G, Fickert P, Silbert D, Fuchsbichler A, Marschall HU, Zatloukal K, et al. Adaptive changes in hepatobiliary transporter expression in primary biliary cirrhosis. $\mathbf{J}$ Hepatol 2003;38(6):717-27.

22. Eloranta JJ, Jung D, Kullak-Ublick GA. The human Na+-taurocholate cotransporting polypeptide gene is activated by glucocorticoid receptor and peroxisome proliferatoractivated receptor-gamma coactivator-1alpha, and suppressed by bile acids via a small heterodimer partner-dependent mechanism. Mol Endocrinol 2006;20(1):65-79.

23. Seol W, Choi HS, Moore DD. An orphan nuclear hormone receptor that lacks a DNA binding domain and heterodimerizes with other receptors. Science 1996;272(5266):1336-9.

24. Goodwin B, Jones SA, Price RR, Watson MA, McKee DD, Moore LB, et al. A regulatory cascade of the nuclear receptors FXR, SHP-1, and LRH-1 represses bile acid biosynthesis. Mol Cell 2000;6(3):517-26.

25. Lu TT, Makishima M, Repa JJ, Schoonjans K, Kerr TA, Auwerx J, et al. Molecular basis for feedback regulation of bile acid synthesis by nuclear receptors. Mol Cell 2000;6(3):507-15. 
26. Borgius LJ, Steffensen KR, Gustafsson JA, Treuter E. Glucocorticoid signaling is perturbed by the atypical orphan receptor and corepressor SHP. J Biol Chem 2002;277(51):49761-6.

27. Jung D, Kullak-Ublick GA. Hepatocyte nuclear factor 1 alpha: a key mediator of the effect of bile acids on gene expression. Hepatology 2003;37(3):622-31.

28. Popowski K, Eloranta JJ, Saborowski M, Fried M, Meier PJ, Kullak-Ublick GA. The human organic anion transporter 2 gene is transactivated by hepatocyte nuclear factor- 4 alpha and suppressed by bile acids. Mol Pharmacol 2005;67(5):1629-38.

29. Saborowski M, Kullak-Ublick GA, Eloranta JJ. The human organic cation transporter-1 gene is transactivated by hepatocyte nuclear factor-4alpha. J Pharmacol Exp Ther $2006 ; 317(2): 778-85$.

30. Neimark E, Chen F, Li X, Shneider BL. Bile acid-induced negative feedback regulation of the human ileal bile acid transporter. Hepatology 2004;40(1):149-56.

31. Hruz P, Zimmermann C, Gutmann H, Degen L, Beuers U, Terracciano L, et al. Adaptive regulation of the ileal apical sodium dependent bile acid transporter (ASBT) in patients with obstructive cholestasis. Gut 2006;55(3):395-402.

32. Jung D, Fantin AC, Scheurer U, Fried M, Kullak-Ublick GA. Human ileal bile acid transporter gene ASBT (SLC10A2) is transactivated by the glucocorticoid receptor. Gut 2004;53(1):78-84. 